\title{
PENERAPAN METODE TOPSIS DALAM PENENTUAN SKALA PRIORITAS REHABILITASI JARINGAN IRIGASI DAERAH KETIAT B BENGKAYANG
}

\author{
Abdul Hamid \\ Fakultas Teknik, Program Studi Teknik Sipil \\ Universitas Tanjungpura Pontianak \\ Email: hamidftuntan@yahoo.co.id \\ Dwi Marisa Midyanti \\ FMIPA, Program Studi Rekayasa Sistem Komputer \\ Universitas Tanjungpura Pontianak \\ Email: dwi.marisa@siskom.untan.ac.id
}

\begin{abstract}
ABSTRAK
Jaringan irigasi dibangun oleh pemerintah untuk menunjang kegiatan perkebunan, pertanian, dan keperluan lainnya. Kerusakan jaringan irigasi dapat terjadi karena faktor usia bangunan, curah hujan yang tinggi, kebocoran saluran, endapan lumpur dan sampah. Jaringan irigasi yang rusak memerlukan rehabilitasi agar fungsi dan pelayanan irigasi dapat kembali seperti semula. Penelitian ini bertujuan untuk mengetahui skala prioritas rehabilitasi jaringan irigasi daerah Ketiat B Bengkayang dengan menggunakan metode TOPSIS. TOPSIS merupakan salah satu metode dalam penyelesaian permasalan Multi Attribute Decision Making (MADM). Empat kriteria digunakan dalam penelitian ini yaitu Kesediaan air, produktivitas padi, sarana operasi dan kondisi jaringan fisik. Alternatif pilihan berjumlah 36 alternatif. Hasil penelitian dengan menggunakan metode TOPSIS menunjukkan prioritas rehabilitasi daerah Ketiat B Bengkayang adalah perbaikan Bendungan - Pengambil Bebas (Sungai).
\end{abstract}

Kata kunci: rehabilitasi jaringan irigasi; skala prioritas; TOPSIS.

\begin{abstract}
Irrigation networks are built by the government to support plantations, agriculture, and other needs. Irrigation network damage can occur because of the age of the building, rainfall, leakage channel, sedimentation, and garbage. Rehabilitation of irrigation networks is needed so the functions and services of irrigation can return to normal. This study aims to determine the priority scale of irrigation network rehabilitation in Ketiat B Bengkayang using the TOPSIS method. TOPSIS is one method of solving MultiAttribute Decision Making (MADM) problems. The four criteria used in this study are water availability, rice productivity, operational facilities, and physical network conditions. Alternative choices are 36 alternatives. The results of the research using TOPSIS method show the priority of the rehabilitation Ketiat B Bengkayang area is to repair the Dam - Irrigation sluice gate.
\end{abstract}

Keywords: rehabilitation of irrigation networks; priority scale; TOPSIS.

\section{PENDAHULUAN}

Irigasi adalah usaha penyediaan,pengaturan, dan pembuangan air irigasi untuk menunjang pertanian yang jenisnya meliputi irigasi permukaan, irigasi rawa, irigasi air bawah tanah, irigasi pompa, dan irigasi tambak. Sistem irigasi meliputi prasarana irigasi, air irigasi, manajemen irigasi, kelembagaan pengelolaan irigasi, dan sumber daya manusia [1].

Rehabilitasi jaringan irigasi dilaksanakan berdasarkan urutan prioritas kebutuhan perbaikan irigasi yang ditetapkan pemerintah, pemerintah provinsi, dan pemerintah kabupaten/kota sesuai dengan kewenangannya setelah memperhatikan pertimbangan kondisi irigasi, dan sesuai dengan dengan norma, standar, pedoman, dan manual yang ditetapkan oleh Menteri [1]. Penetapan urutan prioritas kebutuhan rehabilitasi didasarkan pada tingkat kerusakan jaringan irigasi, luas pelayanan yang terpengaruh akibat kerusakan, keterbatasan pembiayaan, dan besarnya dampak yang timbul akibat penundaan perbaikan kerusakan [1]. Pemerintah semestinya mengetahui terlebih dahulu skala prioritas rehabilitasi jaringan irigasi sebelum melakukan perancangan, pemeliharaan, dan pembangunan jaringan irigasi.

Ketiat B merupakan salah satu daerah di Kabupaten Bengkayang Kalimantan Barat yang memiliki potensi pengembangan dalam pertanian dan perkebunan yang besar sehingga menjadi daerah prioritas 
rehabilitasi jaringan irigasi. Ketiat B belum dapat berfungsi secara maksimal karena bendung, bangunan lain, saluran dan pintu air banyak mengalami kerusakan. Pemerintah Kabupaten Bengkayang memiliki keterbatasan keuangan sehingga memerlukan kebijakan dalam menentukan skala prioritas rehabilitasi irigasi [2]. Savitri [2] menggunakan metode AHP untuk menentukan skala prioritas rehabilitasi jaringan irigasi di daerah Ketiat B Bengkayang. Kriteria yang digunakan sebanyak empat kriteria yaitu kesediaan air, produktivitas padi, sarana operasi dan kondisi jaringan fisik, dan alternatif yang digunakan sebanyak empat alternatif yaitu bangunan bendung, bangunan pelengkap, saluran dan sumber daya manusia (SDM). Hasil dari penelitian ini adalah prioritas pertama yang didapat yaitu alternatif bangunan bendung dengan nilai bobot global 0,6417 .

Penentuan prioritas pernah juga diteliti [3] di Kabupaten Pohuwato Provinsi Gorontalo untuk menentukan prioritas pembangunan pada Desa Ayula Kecamatan Randang menggunakan metode Promethee. Metode Promethee merupakan salah satu metode penyelesaian permasalahan dalam Multi Criteria Decission Making (MCDM) yang dapat menyelesaikan permasalahan penentuan prioritas. Metode lain dalam MCDM adalah Technique for Order Preference by Similarity to Ideal Solution (TOPSIS).

TOPSIS didasarkan pada konsep dimana alternatif terpilih yang terbaik tidak hanya memiliki jarak terpendek dari solusi ideal positif namun juga memiliki jarak terpanjang dari solusi ideal negatif [4].

Metode TOPSIS telah banyak digunakan dalam penelitian sebagai metode pengambilan keputusan, diantaranya dalam penelitian penentuan prioritas kondisi rumah [5], penelitian untuk mengetahui bakat akademik anak [6], penelitian pada desa Panca Karsa II untuk penentuan keluarga miskin [7], penelitian untuk pemilihan mobil murah ramah lingkungan [8], penelitian pada SMA Al Washliyah Tanjung Morawa untuk sistem penerimaan pegawai [9], dan penelitian bagi penentuan kawasan pengembangan argoindustri bioenergi kelapa sawit di Provinsi Riau [10].

Pada penelitian ini TOPSIS akan digunakan untuk menentukan prioritas rehabilitasi jaringan irigasi daerah Ketiat B Bengkayang.

\section{METODOLOGI PENELITIAN}

Penelitian ini menggunakan data kuesioner dari penelitian Savitri[2]. Dari data kuesioner tersebut ditentukan empat kriteria dan 36 alternatif data yang akan diolah. Dengan menggunakan metode TOPSIS, akan didapatkan urutan prioritas rehabilitasi jaringan irigasi di daerah Ketiat B Bengkayang.

Langkah-langkah prosedur TOPSIS adalah [4]:

a) Hitung ranting kinerja ternormalisasi $\left(r_{i j}\right)$ setiap $A_{i}$ dengan persamaan 1 .

$$
r_{i j}=\frac{x_{i j}}{\sqrt{\sum_{i=1}^{m} x_{i j}^{2}}} ; \text { dengan } \mathrm{i}=1,2, \ldots, \mathrm{m} ; \text { dan } \mathrm{j}=1,2, \ldots, \mathrm{n}
$$

dimana $x_{i j}$ merupakan data masukan

b) Hitung ranting bobot ternormalisasi (yij) dengan persamaan 2 .

$\mathrm{y}_{\mathrm{ij}}=\mathrm{w}_{\mathrm{j}} . \mathrm{r}_{\mathrm{ij}}$

dengan $\sum_{j=1}^{n} w_{j}=1$

$\mathrm{w}_{\mathrm{j}}$ adalah bobot dari setiap kriteria dengan total nilainya adalah 1 .

c) Tentukan matriks solusi ideal positif dengan persamaan (3) dan (5), dan matriks solusi ideal negatif dengan persamaan (4) dan (6).

$$
\begin{aligned}
& \mathrm{A}^{+}=\left(\mathrm{y}_{1}^{+}, \mathrm{y}_{2}{ }^{+}, \ldots, \mathrm{y}_{\mathrm{n}}^{+}\right) \\
& \mathrm{A}^{-}=\left(\mathrm{y}_{1}^{-}, \mathrm{y}_{2}^{-}, \ldots, \mathrm{y}_{\mathrm{n}}^{-}\right)
\end{aligned}
$$

dengan

$$
\begin{aligned}
& y_{j}^{+}= \begin{cases}\max _{i} y_{i j} ; & \text { Jika } \mathrm{j} \text { adalah atribut keuntungan } \\
\min _{i} y_{i j} ; & \text { Jika } \mathrm{j} \text { adalah atribut biaya }\end{cases} \\
& y_{j}^{-}= \begin{cases}\max _{i} y_{i j} ; & \text { Jika } \mathrm{j} \text { adalah atribut biaya } \\
\min _{i} y_{i j} ; & \text { Jika } \mathrm{j} \text { adalah atribut keuntungan }\end{cases}
\end{aligned}
$$


Pada $\mathrm{y}_{\mathrm{j}}{ }^{+}$, nilai maksimum diambil untuk atribut keuntungan(benefit), dan nilai minimum diambil untuk atribut biaya(cost). Sementara pada $\mathrm{y}_{\mathrm{j}}^{-}$, nilai maksimum diambil untuk atribut biaya dan nilai minimum diambil untuk atribut keuntungan.

d) Hitung jarak antara nilai setiap alternatif dengan matriks solusi ideal positif $\left(D_{i}^{+}\right)$dan matriks solusi ideal negatif $\left(D_{i}^{-}\right)$menggunakan persamaan 7 dan 8 .

$$
\begin{gathered}
D_{i}^{+}=\sqrt{\sum_{j=1}^{n}\left(y_{i}^{+}-y_{i j}\right)^{2}} ; \quad \mathrm{i}=1,2, \ldots, \mathrm{m} \\
D_{i}^{-}=\sqrt{\sum_{j=1}^{n}\left(y_{i j}-y_{i}^{-}\right)^{2}} ; \quad \mathrm{i}=1,2, \ldots, \mathrm{m}
\end{gathered}
$$

e) Menggunakan persamaan 9 untuk menentukan nilai preferensi untuk setiap alternatif $\left(V_{i}\right)$

$$
V_{i}=\frac{D_{i}^{-}}{D_{i}^{-}+D_{i}^{+}} \quad ; \quad \mathrm{i}=1,2, \ldots, \mathrm{m}
$$

Nilai $V_{i}$ yang paling besar yang didapat dari persamaan 9 menunjukkan bahwa atlernatif $\mathrm{A}_{\mathrm{i}}$ lebih dipilih.

\section{HASIL DAN PEMBAHASAN}

Penelitian ini menggunakan empat kriteria yaitu kesediaan air, produktivitas padi, sarana operasi dan kondisi jaringan fisik. Empat kriteria tersebut diinisialkan sebagai berikut :

$\mathrm{Kr} 1=$ Kesediaan ir

$\mathrm{Kr} 2$ = Produktivitas padi

$\mathrm{Kr} 3$ = Sarana operasi

$\mathrm{Kr} 4=$ Kondisi jaringan fisik

Data yang digunakan sebanyak 36 alternatif terlihat pada tabel 1 . 
Tabel 1. Alternatif rehabilitasi jaringan irigasi

\begin{tabular}{lc}
\hline \multicolumn{1}{c}{ Alternatif } & Kode \\
\hline Bendungan - Pengambilan Bebas (Sungai) & AA1 \\
Bangunan Pelengkap - Pengambilan Bebas (Sungai) & AA2 \\
Saluran - Pengambilan Bebas (Sungai) & AA3 \\
SDM - Pengambilan Bebas (Sungai) & AA4 \\
Bendungan - Air Tanah & BA1 \\
Bangunan Pelengkap - Air Tanah & BA2 \\
Saluran - Air Tanah & BA3 \\
SDM - Air Tanah & BA4 \\
Bendungan - Intensitas Tanam & CA1 \\
Bangunan Pelengkap - Intensitas Tanam & CA2 \\
Saluran - Intensitas Tanam & CA3 \\
SDM - Intensitas Tanam & CA4 \\
Bendungan - Hasil Panen & DA1 \\
Bangunan Pelengkap - Hasil Panen & DA2 \\
Saluran - Hasil Panen & DA3 \\
SDM - Hasil Panen & DA4 \\
Bendungan - Peralatan & EA1 \\
Bangunan Pelengkap - Peralatan & EA2 \\
Saluran - Peralatan & EA3 \\
SDM - Peralatan & EA4 \\
Bendungan - Baik & FA1 \\
Bangunan Pelengkap - Baik & FA2 \\
Saluran - Baik & FA3 \\
SDM - Baik & FA4 \\
Bendungan - Rusak Ringan & GA1 \\
Bangunan Pelengkap - Rusak Ringan & GA2 \\
Saluran - Rusak Ringan & GA3 \\
SDM - Rusak Ringan & GA4 \\
Bendungan - Rusak Sedang & HA1 \\
Bangunan Pelengkap - Rusak Sedang & IA4 \\
Saluran - Rusak Sedang & \\
SDM - Rusak Sedang & HA3 \\
Bendungan-Rusak Berat & HA4 \\
Bangunan Pelengkap-Rusak Berat & IA1 \\
Saluran-Rusak Berat & IA \\
SDM-Rusak Berat &
\end{tabular}

Setelah kriteria dan alternatif ditentukan, hitung bobot kriteria yang diambil dari data kuisioner. Tabel 2 merupakan bobot kriteria.

Tabel 2. Bobot kriteria penelitian

\begin{tabular}{rrrrrr}
\hline & $\boldsymbol{K} \boldsymbol{r} \mathbf{1}$ & $\boldsymbol{K} \boldsymbol{r} \mathbf{2}$ & $\boldsymbol{K r} \mathbf{3}$ & $\boldsymbol{K r} \mathbf{4}$ & $\boldsymbol{B}$ Bobot \\
\hline$K r 1$ & 0 & 2.19849 & 2.70537 & 2.08865 & 0.40017 \\
$K r 2$ & 0.45486 & 0 & 2.37174 & 0.40430 & 0.18490 \\
$K r 3$ & 0.36963 & 0.42163 & 0 & 0.31308 & 0.06320 \\
$K r 4$ & 0.47878 & 2.47342 & 3.19403 & 0 & 0.35174 \\
\hline \multicolumn{7}{c}{ TOTAL } \\
\hline
\end{tabular}

Data kuisioner kemudian diolah berdasarkan kebutuhan untuk data penelitian. Hasilnya terdapat pada tabel 3 .

Tabel 3. Data nilai alternatif terhadap kriteria

\begin{tabular}{clcccc}
\hline Kode & $\boldsymbol{K} \boldsymbol{r} \mathbf{1}$ & $\boldsymbol{K r} \mathbf{2}$ & \multicolumn{1}{c}{$\boldsymbol{K r} \mathbf{3}$} & $\boldsymbol{K r} \boldsymbol{4}$ \\
\hline AA1 & 3.76703 & & 0 & 0 & 0 \\
AA2 & 1.61914 & & 0 & 0 & 0 \\
AA3 & 1.12960 & & 0 & 0 & 0 \\
AA4 & 0.36369 & & 0 & 0 & 0 \\
\hline
\end{tabular}




\begin{tabular}{|c|c|c|c|c|}
\hline Kode & $K r 1$ & $K r 2$ & Kr3 & $K r 4$ \\
\hline BA1 & 0.64920 & 0 & 0 & 0 \\
\hline BA2 & 0.31846 & 0 & 0 & 0 \\
\hline BA3 & 0.20184 & 0 & 0 & 0 \\
\hline BA4 & 0.06596 & 0 & 0 & 0 \\
\hline CA1 & 0 & 2.4482 & 0 & 0 \\
\hline $\mathrm{CA} 2$ & 0 & 0.8002 & 0 & 0 \\
\hline CA3 & 0 & 0.4864 & 0 & 0 \\
\hline CA4 & 0 & 0.2066 & 0 & 0 \\
\hline DA1 & 0 & 3.0988 & 0 & 0 \\
\hline DA2 & 0 & 0.9045 & 0 & 0 \\
\hline DA3 & 0 & 0.4292 & 0 & 0 \\
\hline DA4 & 0 & 0.3458 & 0 & 0 \\
\hline EA1 & 0 & 0 & 2.3673 & 0 \\
\hline EA2 & 0 & 0 & 0.9035 & 0 \\
\hline EA3 & 0 & 0 & 0.5945 & 0 \\
\hline EA4 & 0 & 0 & 0.2365 & 0 \\
\hline FA1 & 0 & 0 & 2.0541 & 0 \\
\hline FA2 & 0 & 0 & 0.9304 & 0 \\
\hline FA3 & 0 & 0 & 0.5245 & 0 \\
\hline FA4 & 0 & 0 & 0.2466 & 0 \\
\hline GA1 & 0 & 0 & 0 & 0.2985 \\
\hline GA2 & 0 & 0 & 0 & 0.0970 \\
\hline GA3 & 0 & 0 & 0 & 0.0851 \\
\hline GA4 & 0 & 0 & 0 & 0.0306 \\
\hline HA1 & 0 & 0 & 0 & 0.2999 \\
\hline HA2 & 0 & 0 & 0 & 0.1427 \\
\hline HA3 & 0 & 0 & 0 & 0.0963 \\
\hline HA4 & 0 & 0 & 0 & 0.0357 \\
\hline IA1 & 0 & 0 & 0 & 1.1498 \\
\hline IA2 & 0 & 0 & 0 & 0.4719 \\
\hline IA3 & 0 & 0 & 0 & 0.3229 \\
\hline IA4 & 0 & 0 & 0 & 0.1332 \\
\hline
\end{tabular}

Setelah didapat bobot kriteria dan data alternatif terhadap kriteria, maka langkah pertama dalam metode TOPSIS adalah menghitung ranting kinerja ternormalisasi setiap $\mathrm{A}_{\mathrm{i}}$ berdasarkan persamaan 1. Langkah kedua dari metode TOPSIS adalah meghitung ranting bobot ternormalisasi dengan persamaan 2. Langkah ketiga dari metode TOPSIS adalah menentukan matriks solusi ideal positif dengan menggunakan persamaan 3 dan 5, dan solusi ideal negatif dengan persamaan 4 dan 6. Empat kriteria dalam penelitian ini merupakan atribut keuntungan. Langkah ke empat adalah menghitung jarak antara nilai setiap alternatif dengan matriks solusi ideal positif $\left(D_{i}^{+}\right)$dan matriks solusi ideal negatif $\left(D_{i}^{-}\right)$menggunakan persamaan 7 dan persamaan 8. Langkah kelima dari metode TOPSIS adalah menggunakan persamaan 9 untuk menentukan nilai preferensi untuk setiap alternatif $\left(V_{i}\right)$. Hasil perhitungan jarak antar nilai alternatif dan nilai preferensi setiap alternatif terdapat pada tabel 4.

Tabel 4. Hasil perhitungan jarak antar nilai alternatif dan nilai preferensi

\begin{tabular}{cccc}
\hline Kode & $\boldsymbol{D}_{\boldsymbol{i}}^{+}$ & $\boldsymbol{D}_{\tilde{\boldsymbol{i}}}^{-}$ & $\boldsymbol{V}_{\boldsymbol{i}}$ \\
\hline AA1 & 0.5506 & 1.3101 & 0.70409586 \\
AA2 & 1.2016 & 0.2420 & 0.16765287 \\
AA3 & 1.3133 & 0.1178 & 0.08231769 \\
AA4 & 1.4098 & 0.0122 & 0.00858739 \\
BA1 & 1.3853 & 0.0389 & 0.02732069 \\
BA2 & 1.4124 & 0.0094 & 0.00658527 \\
BA3 & 1.4176 & 0.0038 & 0.00264614 \\
BA4 & 1.4207 & 0.0004 & 0.00028266 \\
CA1 & 1.3660 & 0.2639 & 0.16190227 \\
\hline
\end{tabular}




\begin{tabular}{|c|c|c|c|}
\hline Kode & $D_{i}^{+}$ & $D_{\bar{i}}^{\overline{1}}$ & $V_{i}$ \\
\hline $\mathrm{CA} 2$ & 1.4129 & 0.0282 & 0.01956018 \\
\hline CA3 & 1.4180 & 0.0104 & 0.00729272 \\
\hline CA4 & 1.4205 & 0.0019 & 0.00132059 \\
\hline DA1 & 1.3567 & 0.4228 & 0.23757905 \\
\hline DA2 & 1.4108 & 0.0360 & 0.02489665 \\
\hline DA3 & 1.4187 & 0.0081 & 0.00568543 \\
\hline DA4 & 1.4195 & 0.0053 & 0.00369425 \\
\hline EA1 & 1.4175 & 0.1012 & 0.06663047 \\
\hline EA2 & 1.4201 & 0.0147 & 0.01027323 \\
\hline EA3 & 1.4206 & 0.0064 & 0.00447276 \\
\hline EA4 & 1.4210 & 0.0010 & 0.00071023 \\
\hline FA1 & 1.4177 & 0.0762 & 0.05099880 \\
\hline FA2 & 1.4200 & 0.0156 & 0.01088797 \\
\hline FA3 & 1.4207 & 0.0050 & 0.00348482 \\
\hline FA4 & 1.4210 & 0.0011 & 0.00077239 \\
\hline GA1 & 1.4158 & 0.0228 & 0.01582724 \\
\hline GA2 & 1.4205 & 0.0024 & 0.00168919 \\
\hline GA3 & 1.4206 & 0.0019 & 0.00130252 \\
\hline GA4 & 1.4210 & 0.0002 & 0.00016821 \\
\hline HA1 & 1.4158 & 0.0230 & 0.01597189 \\
\hline HA2 & 1.4198 & 0.0052 & 0.00365120 \\
\hline HA3 & 1.4205 & 0.0024 & 0.00166645 \\
\hline HA4 & 1.4210 & 0.0003 & 0.00022945 \\
\hline IA1 & 1.3803 & 0.3379 & 0.19664475 \\
\hline IA2 & 1.4086 & 0.0569 & 0.03883880 \\
\hline IA3 & 1.4150 & 0.0267 & 0.01848709 \\
\hline IA4 & 1.4200 & 0.0045 & 0.00318392 \\
\hline
\end{tabular}

Rekomendasi untuk penentuan skala prioritas rehabilitasi jaringan irigasi daerah Ketiat B Bengkayang dapat dilihat pada tabel 5.

Tabel 5. Rekomendasi skala prioritas jaringan irigasi

\begin{tabular}{cclc}
\hline NO & Nilai Preferensi Kriteria & \multicolumn{1}{c}{ Nama Kriteria } & Kode \\
\hline 1 & 0.70410 & Bendungan - Pengambilan Bebas (Sungai) & AA1 \\
2 & 0.23758 & Bendungan - Hasil Panen & DA1 \\
3 & 0.19664 & Bendungan - Rusak Berat & IA1 \\
4 & 0.16765 & Bangunan Pelengkap - Pengambilan Bebas (Sungai) & AA2 \\
5 & 0.16190 & Bendungan - Intensitas Tanam & CA1 \\
6 & 0.08232 & Saluran - Pengambilan Bebas (Sungai) & AA3 \\
7 & 0.06663 & Bendungan - Peralatan & EA1 \\
8 & 0.05100 & Bendungan - Baik & FA1 \\
9 & 0.03884 & Bangunan Pelengkap - Rusak Berat & IA2 \\
10 & 0.02732 & Bendungan - Air Tanah & BA1 \\
11 & 0.02490 & Bangunan Pelengkap - Hasil Panen & DA2 \\
12 & 0.01956 & Bangunan Pelengkap - Intensitas Tanam & CA2 \\
13 & 0.01849 & Saluran -Rusak Berat & IA3 \\
14 & 0.01597 & Bendungan - Rusak Sedang & HA1 \\
15 & 0.01583 & Bendungan - Rusak Ringan & GA1 \\
16 & 0.01089 & Bangunan Pelengkap - Baik & FA2 \\
17 & 0.01027 & Bangunan Pelengkap - Peralatan & EA2 \\
18 & 0.00859 & SDM - Pengambilan Bebas (Sungai) & AA4 \\
19 & 0.00729 & Saluran - Intensitas Tanam & CA3 \\
\hline
\end{tabular}




\begin{tabular}{cclc}
\hline NO & Nilai Preferensi Kriteria & \multicolumn{1}{c}{ Nama Kriteria } & Kode \\
\hline 20 & 0.00659 & Bangunan Pelengkap - Air Tanah & BA2 \\
21 & 0.00569 & Saluran - Hasil Panen & DA3 \\
22 & 0.00447 & Saluran - Peralatan & EA3 \\
23 & 0.00369 & SDM - Hasil Panen & DA4 \\
24 & 0.00365 & Bangunan Pelengkap - Rusak Sedang & HA2 \\
25 & 0.00348 & Saluran - Baik & FA3 \\
26 & 0.00318 & SDM - Rusak Berat & IA4 \\
27 & 0.00265 & Saluran - Air Tanah & BA3 \\
28 & 0.00169 & Bangunan Pelengkap - Rusak Ringan & GA2 \\
29 & 0.00167 & Saluran - Rusak Sedang & HA3 \\
30 & 0.00132 & SDM - Intensitas Tanam & CA4 \\
31 & 0.00130 & Saluran - Rusak Ringan & GA3 \\
32 & 0.00077 & SDM - Baik & FA4 \\
33 & 0.00071 & SDM - Peralatan & EA4 \\
34 & 0.00028 & SDM - Air Tanah & BA4 \\
35 & 0.00023 & SDM - Rusak Sedang & HA4 \\
36 & 0.00017 & SDM - Rusak Ringan & GA4 \\
\hline
\end{tabular}

Dari hasil tabel 5, maka untuk rehabilitasi jaringan irigasi daerah Ketiat B Bengkayang berdasarkan metode TOPSIS yang menjadi prioritas adalah Bendungan - Pengambilan Bebas (Sungai) dengan nilai preferensi kriteria sebesar 0,70410 .

\section{KESIMPULAN}

Pada penelitian ini digunakan metode TOPSIS dalam penentuan skala prioritas rehabilitasi jaringan irigasi daerah Ketiat B Bengkayang. Terdapat 4 kriteria dan 36 alternatif data yang diolah. Berdasarkan hasil perhitungan metode TOPSIS, didapat alternatif yang terbaik yaitu rehabilitasi BendunganPengambil Bebas (Sungai) dengan nilai preferensi tertinggi sebesar 0,70410.

\section{UCAPAN TERIMA KASIH}

Terima kasih kepada Ibu Endang Savitri,S.T., M.T., atas kesediaannya memberikan bantuan berupa data dalam penelitian ini.

\section{DAFTAR PUSTAKA}

[1] Presiden Republik Indonesia. (2006). Peraturan Pemerintah Republik Indonesia Nomor 20 Tahun 2006 tentang Irigasi, Jakarta : Menteri Hukum dan Hak Asasi Manusia.

[2] Savitri, E. (2017) Penentuan Skala Prioritas Pada Rehabilitasi Jaringan Irigasi Di Kabupaten Bengkayang (Studi Kasus : Daerah Irigasi Ketiat B). Universitas Tanjungpura Pontianak.

[3] Karim, J. (2018) 'Sistem Pendukung Keputusan Penentuan Prioritas Pembangunan Menggunakan Metode Promethee Pada Desa Ayula Kecamatan Randangan Kabupaten Pohuwato Provinsi Gorontalo', ILKOM Jurnal Ilmiah Volume, 10(1), pp. 86-91.

[4] Kusumadewi, S., et al. (2006). Fuzzy Multi-Attribute Decision Making (Fuzzy MADM). Yogyakarta : Graha Ilmu.

[5] Chamid, A. A. (2016) 'Penerapan Metode Topsis Untuk Menentukan Prioritas Kondisi Rumah', Jurnal Simetris, 7(2), pp. 537-544.

[6] Warjiyono (2016) 'Sistem Pendukung Keputusan Untuk Mengetahui Bakat Akademik Anak Menggunakan Metode Topsis', Information System For Educators And Professionals, 1(1), pp. 1-8.

[7] Muzakkir, I. (2017) 'Penerapan Metode Topsis Untuk Sistem Pendukung Keputusan Penentuan Keluarga Miskin Pada Desa Panca Karsa II’, ILKOM Jurnal Ilmiah Volume, 9(3), pp. 274-281.

[8] Mardiana, T. (2018) 'Sistem Pendukung Keputusan Pemilihan Mobil Murah Ramah Lingkungan Menggunakan Metode Topsis', Jurnal TECHNO Nusa Mandiri, 15(1), pp. 37-42.

[9] Sriani and Putri, R. A. (2018) 'Analisa Sistem Pendukung Keputusan Menggunakan Metode Topsis Untuk Sistem Penerimaan Pegawai Pada Sma Al Washliyah Tanjung Morawa', Algoritma : Jurnal Ilmu Komputer dan Informatika, 02(01), pp. 40-46. 
Jurnal SIMETRIS, Vol. 10 No. 1 April 2019

P-ISSN: 2252-4983, E-ISSN: 2549-3108

[10] Papilo, P. et al. (2018) 'Penerapan Fuzzy TOPSIS dalam Penentuan Lokasi Kawasan Pengembangan Rantai Pasok Bioenergi Kelapa Sawit', Agritech, 38(1), pp. 79-87. 